\title{
The study of sorption of caesium radionuclides by "T-55" ferrocyanide sorbent from various types of liquid radioactive wastes
}

\author{
V. S. Semenischev • A. V. Voronina • \\ A. A. Bykov
}

Received: 13 July 2012/Published online: 25 October 2012

(C) Akadémiai Kiadó, Budapest, Hungary 2012

\begin{abstract}
The sorption of caesium by T-55 sorbent from different types of liquid radioactive wastes is studied. It is shown that the sorbent can be used for extraction of caesium from high level acidic and saline solutions and also for decontamination of caesium contaminated waters containing surfactants and EDTA.
\end{abstract}

Keywords Liquid radioactive wastes - Decontamination · Sorption · Nickel-potassium ferrocyanide based on hydrated titanium dioxide $\cdot$ Cs-137 .

Disrtibution coefficient · Nitric acid solutions .

Sodium nitrate solutions · Alkaline solutions · Surfactants · EDTA

\section{Introduction}

Accumulation of considerable amounts of various level liquid radioactive wastes (LRW) results from radiochemical treatment of irradiated nuclear fuel (INF). Such longlived radionuclides as ${ }^{137} \mathrm{Cs}$ (its contribution to overall gamma activity of 5 years old INF is approximately $95 \%$ ) and ${ }^{90} \mathrm{Sr}$ make the major contribution to specific activity of LRW. The major part of high level LRW accumulating due to PUREX-process, are high level acidic or high saline raffinates, containing up to $8 \mathrm{~mol} \mathrm{~L}-1 \mathrm{HNO}_{3}$ or $\mathrm{NaNO}_{3}$. Radioactive contaminated special sewer water containing surfactants and also solutions after deactivation containing complexing agents [substantially ethylene diamine tetraacetate (EDTA)] have the most importance in practice of low level LRW treatment.

V. S. Semenischev $(\bowtie) \cdot$ A. V. Voronina · A. A. Bykov

Ural Federal University, Ekaterinburg, Russia

e-mail: vovius82@mail.ru
T-55 sorbent was developed by Radiochemistry and Applied Ecology chair of UrFU (Russia) for extraction of caesium from various aqueous media $[1,2]$. This sorbent is a thin-layer nickel-potassium ferrocyanide spreaded via chemical manipulations on the surface of commercially available granulated hydrated titanium dioxide ("Thermoxid-5"). The chemical composition of T-55 sorbent, obtained via X-ray fluorescence analysis, is presented in Table 1.

As it was shown in works $[1,2], \mathrm{T}-55$ sorbent is able to efficiently separate caesuim from water: distribution coefficient is up to $10^{5}-10^{6} \mathrm{~mL} \mathrm{~g}^{-1}$, sorption capacity is up to $270 \mathrm{mg} \mathrm{g}^{-1}$. Previous researches have also shown the high efficiency of using of this sorbent for extraction of caesium from fresh water containing analogue cations $\left(\mathrm{Na}^{+}, \mathrm{K}^{+}\right.$, $\mathrm{NH}_{4}{ }^{+}$) [3], and also the possibility of immobilization of radionuclides with very low leaching rates [4].

The sorption of caesium by T-55 sorbent from various types of LRW subject to concentrations of various contaminants in solution is studied in this work.

\section{Experimental}

Model solutions, containing $\mathrm{HNO}_{3}$ and $\mathrm{NaNO}_{3}$, synthetic powdered laundry detergent as surfactant, EDTA as complexing agent, stable caesium and ${ }^{137} \mathrm{Cs}$ tracer, were used as LRW. Initial concentration was $1 \mathrm{mg} \mathrm{L}^{-1}$ (unless otherwise indicated), that approximately corresponds to $0.1 \mathrm{Ci} \mathrm{L}^{-1}$ of ${ }^{137} \mathrm{Cs}$.

Studies of caesium sorption were performed under static conditions; the following parameters were used: solution volume $V=50 \mathrm{~mL}$, sorbent weight $m=20 \mathrm{mg}$, time $t=1$ week. Determinations of caesium concentration were performed via radioactive-tracer technique using ${ }^{137} \mathrm{Cs}$. 
Table 1 Chemical composition of T-55 sorbent

\begin{tabular}{lllllll}
\hline Element & $\mathrm{K}$ & $\mathrm{Ti}$ & $\mathrm{Fe}$ & $\mathrm{Ni}$ & $\mathrm{Zr}$ & Oxygen and water \\
\hline$\%$ Mass & $0.764 \pm 0.013$ & $>39.63 \pm 0.05$ & $1.256 \pm 0.07$ & $0.469 \pm 0.003$ & $3.713 \pm 0.012$ & To $100 \%$ \\
\hline
\end{tabular}
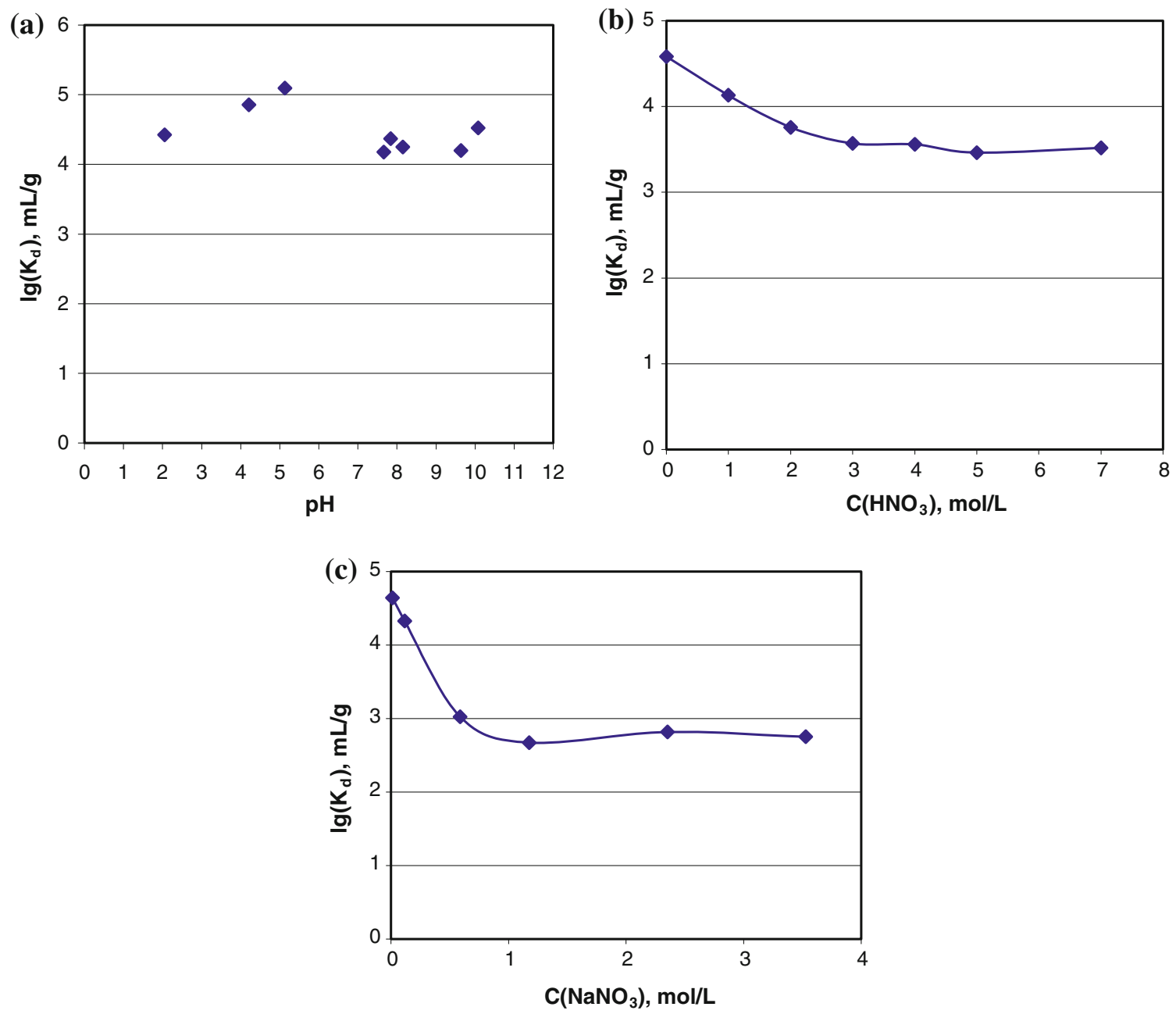

Fig. 1 Dependences of caesium distribution coefficients $K_{\mathrm{d}}$ on $\mathrm{pH}(\mathbf{a})$, concentration of $\mathrm{HNO}_{3}(\mathbf{b})$ and concentration of $\mathrm{NaNO}_{3}(\mathbf{c})$

Samples were measured via beta-radiometry using low background alpha-beta-radiometer "UMF-2000" with semiconductor detector. $\mathrm{pH}$ of solutions were measured on pH-meter 'Satorius PB-11'. Analytical balance 'Shimadzu AW-220' (max. weight $220 \mathrm{~g}, \mathrm{~d}=0.1 \mathrm{mg}$ ) was used for weighting.

The results of static experiences are presented as curves in coordinates " $\lg K_{\mathrm{d}}$-concentration of added compound in solution", where $\lg K_{\mathrm{d}}$ is logarithm of distribution coefficient ( $\mathrm{mL} \mathrm{g}^{-1}$ ) that is to be found in accordance with equilibrium (1):

$k_{\mathrm{d}}=\frac{S}{1-S} \frac{V}{m}$ where $S$ is sorption degree (dimensionless quantity), $V$ is volume of solution $(\mathrm{mL}), m$ is weight of sorbent $(\mathrm{g})$.

The values of sorption degree were calculated according to equilibrium (2):

$S=\frac{I_{\text {in }}-I_{\text {end }}}{I_{\text {in }}}$,

where $I_{\text {in }}$ is count rate of initial solution (after deduction of background), cpm; $I_{\text {end }}$ is count rate of solution after sorption (after deduction of background), cpm.

The isotherm of caesium sorption is presented as curve in coordinates " $\lg C_{\text {solid }}-\lg C_{\text {liquid" }}$ ", where $\lg C_{\text {solid }}$ is logarithm of concentration of caesium in solid phase $(\mathrm{g} / \mathrm{g})$ 

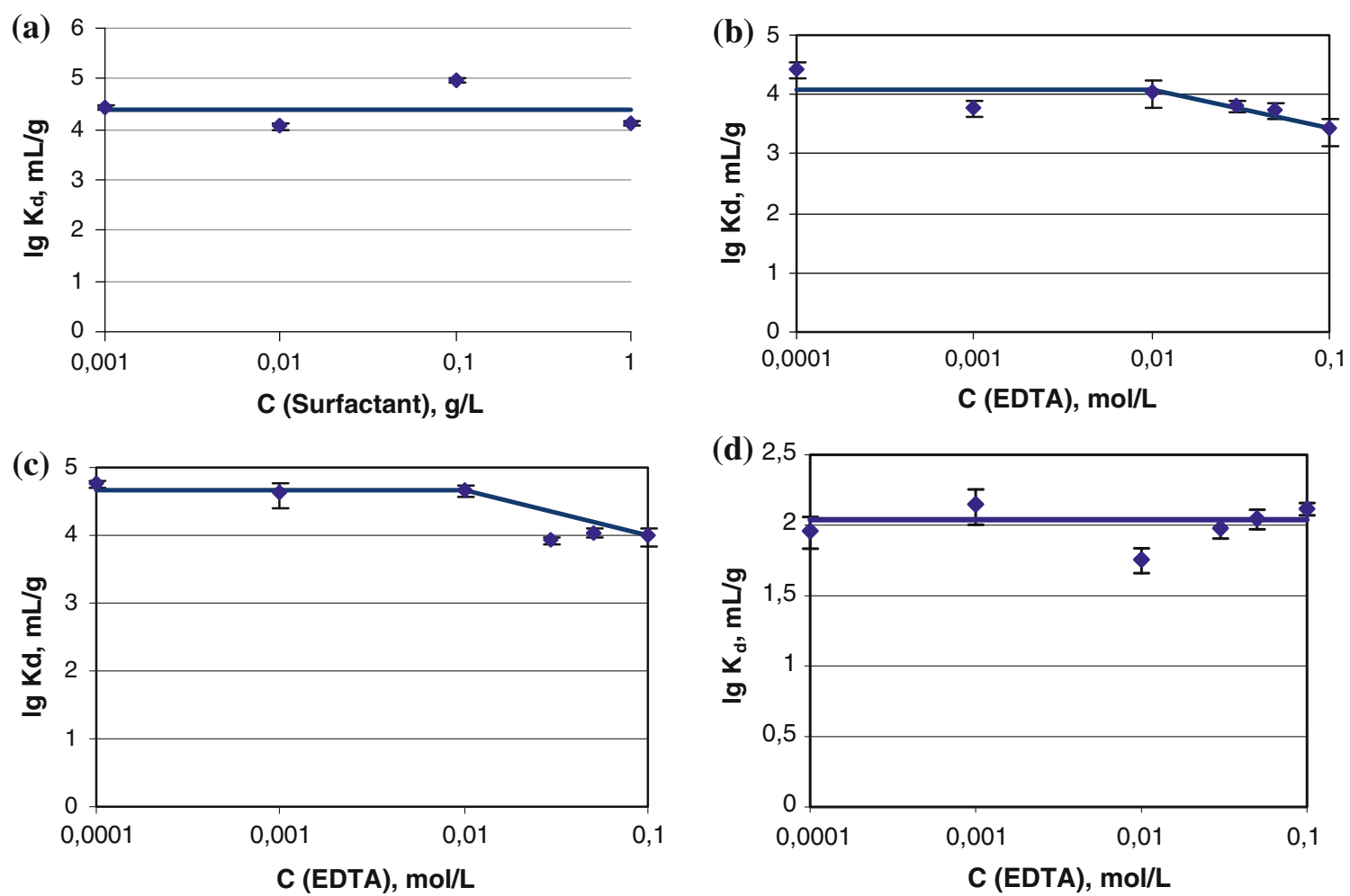

Fig. 2 The dependences of distribution coefficients of caesium on concentration of surfactant (a) and EDTA at initial concentration of caesium of $10^{-3}(\mathbf{b}), 1$ (c) and $100 \mathrm{mg} \mathrm{L}^{-1}(\mathbf{d})$

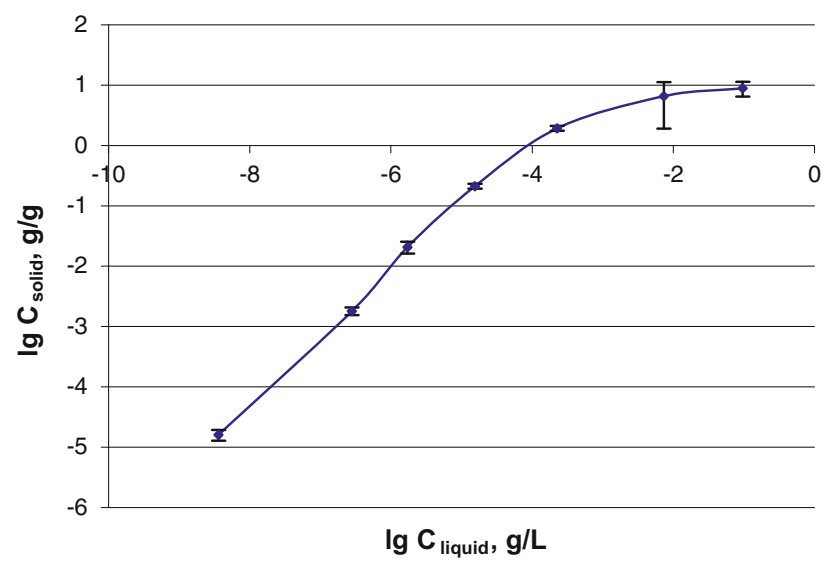

Fig. 3 The isotherm of caesium sorption from solutions containing $0.03 \mathrm{~mol} \mathrm{~L}^{-1}$ EDTA

and $\lg C_{\text {liquid }}$ is logarithm of concentration of caesium in liquid phase $(\mathrm{g} / \mathrm{L})$.

Infrared spectra (IR-spectra) of sorbent samples, saturated under static conditions by caesium from solutions containing $0.03 \mathrm{~mol} \mathrm{~L}^{-1}$ EDTA and various amounts of caesium, were obtained. Measurements were performed in $\mathrm{KBr}$ disk on IR-Raman-Spectrometer 'Vertex-70' with add-on device RAM-II, Bruker, Germany.

\section{Results and discussion}

The dependences of distribution coefficient of caesium on $\mathrm{pH}$ of solution was studied (Fig. 1a). As it was shown there is no any decrease of distribution coefficient of caesium over $\mathrm{pH}$ interval from 1 to 10 .

The dependence of distribution coefficient of caesium on concentration of $\mathrm{HNO}_{3}$ is shown on Fig. $1 \mathrm{~b}$. When the acidity of solution increases the distribution coefficient of caesium smoothly decreases from $3.8 \times 10^{4} \mathrm{~mL} \mathrm{~g}^{-1}$ (neutral solutions) to $3.7 \times 10^{3} \mathrm{~mL} \mathrm{~g}^{-1}$ for $3 \mathrm{M} \mathrm{HNO}_{3}$ and remains almost stable under further increase of acidity. This allows to use T-55 sorbent for extraction of caesium from solutions with concentration of $\mathrm{HNO}_{3}$ up to $7 \mathrm{~mol} \mathrm{~L}^{-1}$. The dependence of distribution coefficient of caesium on concentration of $\mathrm{NaNO}_{3}$ is shown on Fig. 1c. The increasing of $\mathrm{NaNO}_{3}$ concentration up to $0.11 \mathrm{~mol} \mathrm{~L}^{-1}$ leads to decreasing of caesium distribution coefficients due to competitive sorption of sodium. Under higher $\mathrm{NaNO}_{3}$ concentrations (up to $3.5 \mathrm{~mol} \mathrm{~L}{ }^{-1}$ ) distribution coefficient of caesium remains practically invariable at the rate of about $10^{3} \mathrm{~mL} \mathrm{~g}^{-1}$.

The dependence of distribution coefficient of caesium on concentration of surfactant is shown on Fig. 1a. It is obvious that there is no any influence of concentration of 
Fig. 4 IR-spectra of samples of pure T-55 sorbent (1) and T-55 sorbent after sorption of caesium from solutions containing $0.03 \mathrm{~mol} \bullet \mathrm{L}^{-1}$ EDTA and $10^{-5}(2), 1(3)$ and $100 \mathrm{mg} \bullet \mathrm{L}^{-1}(\mathbf{4})$ of caesium

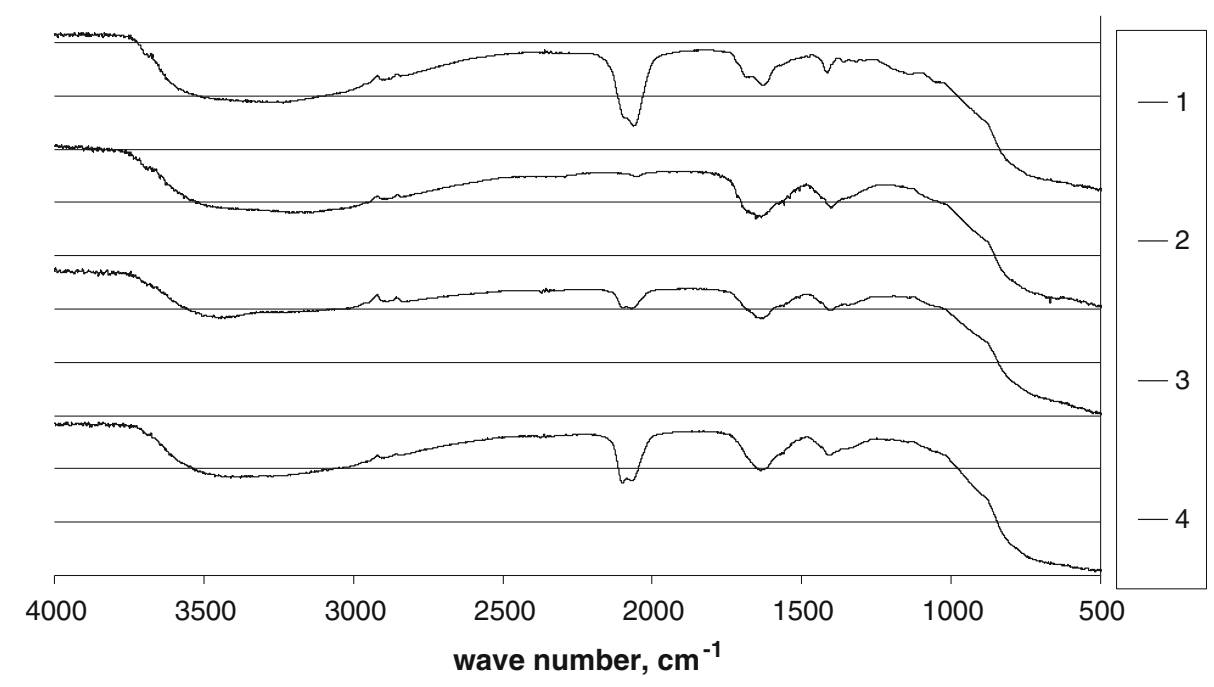

surfactant on caesium sorption under concentration of surfactant up to $1 \mathrm{~g} \mathrm{~L}^{-1}$.

The dependences of distribution coefficient of caesium on concentration of EDTA are shown on Fig. $2 b-d$. In cases of low caesium concentrations (Fig. 2b, c) no influence of EDTA is obtained under concentration of EDTA up to $0.01 \mathrm{~mol} \mathrm{~L}^{-1} ; K_{\mathrm{d}}$ vaues are on the order of $10^{4} \mathrm{~mL} \mathrm{~g}^{-1}$. When concentration of EDTA was $0.05 \mathrm{~mol} \mathrm{~L}^{-1}$ a slight decreasing of distribution coefficients of caesium were obtained. In case of caesium concentration at $100 \mathrm{mg} \mathrm{L}^{-1}$ distribution coefficient doesn't depend on EDTA concentration at all studied concentrations and is on the order of $10^{2} \mathrm{~mL} \mathrm{~g}^{-1}$.

The isotherm of caesium sorption from solutions containing $0.03 \mathrm{~mol} \mathrm{~L}^{-1}$ EDTA is presented on Fig. 3 .

After sorption under low caesium concentrations up to $1 \mathrm{mg} \mathrm{L}^{-1}\left(7.5 \times 10^{-6} \mathrm{~mol} \mathrm{~L}^{-1}\right)$ authors visually observed changes of colour of sorbent, probably due to chemical transformation of ferrocyanide phase of the sorbent, that is additionally corroborated by IR-spectra of samples of the sorbent (see Fig. 4; double absorption peak in the range of $2,000-2,200 \mathrm{~cm}^{-1}$ corresponds to ferrocyanide phase), saturated by caesium from solutions containing $0.03 \mathrm{~mol} \mathrm{~L}^{-1}$ EDTA and various amounts of caesium. As we have shown earlier [2], absorption peaks at 2,060 and 2,092 $\mathrm{cm}^{-1}$ correspond to free ferrocyanide-ion including ones from $\mathrm{K}_{4} \mathrm{Fe}(\mathrm{CN})_{6}$, that presents on the surface and in porous space of T-55 sorbent. Evident correlation between intensity of absorption peak corresponding to ferrocyanide in T-55 sorbent before and after caesium sorption and initial concentration of caesium in solution.

Thus, almost complete disappearance of these absorption peaks was observed under concentration of caesium at $10^{-5} \mathrm{mg} \mathrm{L}^{-1}$ and dramatic decreasing of their intensity at $1 \mathrm{mg} \mathrm{L}^{-1}$. These phenomena are connected with dissolving of $\mathrm{K}_{4} \mathrm{Fe}(\mathrm{CN})_{6}$, crystallized in porous space and probable dissolving of phase of mixed nickel-potassium ferrocyanide. Last process can be conditioned by forming of stable complexes of EDTA with nickel (logarithm of stability constant $\lg K_{1}=18.62$ [5]) and iron (II) $\left(\lg K_{1}=14.20\right.$ [5]) and should be described in accordance with equilibrium (3):

$$
\begin{aligned}
\mathrm{K}_{2} \mathrm{Ni} & {\left[\mathrm{Fe}(\mathrm{CN})_{6}\right] } \\
+ & 2 \mathrm{Na}_{2} \mathrm{H}_{2}\left[\left(\mathrm{OOCCH}_{2}\right)_{2} \mathrm{~N}\left(\mathrm{CH}_{2}\right)_{2} \mathrm{~N}\left(\mathrm{CH}_{2} \mathrm{COO}\right)_{2}\right] \\
\rightarrow & \mathrm{NiH}_{2}\left[(\mathrm{OOCCH})_{2} \mathrm{~N}\left(\mathrm{CH}_{2}\right)_{2} \mathrm{~N}\left(\mathrm{CH}_{2} \mathrm{COO}\right)_{2}\right] \\
& +\mathrm{FeH}_{2}\left[(\mathrm{OOCCH})_{2} \mathrm{~N}\left(\mathrm{CH}_{2}\right)_{2} \mathrm{~N}\left(\mathrm{CH}_{2} \mathrm{COO}\right)_{2}\right] \\
& +4 \mathrm{NaCN}+2 \mathrm{KCN}
\end{aligned}
$$

Suppression of chemical transformation of ferrocyanide phase of the sorbent under concentration of caesium higher than $1 \mathrm{mg} \mathrm{L}^{-1}$ can be explained by the following. Thermodynamic stability of nickel-caesium ferrocyanide appears higher than stability of complexes of EDTA with nickel and iron (II) and very rapid kinetics of sorption allows to form nickel-caesium ferrocyanide before initial ferrocyanide phase disappears. In spite of indubitable partial dissolving of sorption-active phase, sorption isotherm has the appearance of Langmuir isotherm and calculated distribution coefficient of caesium in Henry region is $10^{(4.4 \pm 0.7)} \mathrm{mL} \mathrm{g}^{-1}$. Peculiarities of behaviour of sorption processes in different concentration ranges can be explained by different chemisms of sorption as T-55 is polyfunctioning sorbent.

\section{Conclusions}

Results of researches have shown that T-55 sorbent can be efficiently used for extraction of caesium radionuclides from high level acidic (up to $7 \mathrm{M} \mathrm{HNO}_{3}$ ), saltiness (up to $10 \mathrm{~g} \mathrm{~L}^{-1} \mathrm{NaNO}_{3}$ ) solutions and also from contaminated waters containing surfactants (up to 1 Г/л) and EDTA (up to $0.05 \mathrm{~mol} \mathrm{~L}^{-1}$ ). Thus, $\mathrm{T}-55$ sorbent due to its high 
specificity, selectivity and chemical stability can be efficiently used for decontamination of wide spectrum of LRW from caesium radionuclides.

\section{References}

1. Voronina AV, Betenekov ND, Nogovitsyna EV, Semenistchev VS (2008) Characteristic features of statics and kinetics of caesium sorption with nickel-potassium ferrocyanides based on hydrated titanium and zirconium dioxides/SCI conference: IEX 2008 recent advances in ion exchange theory and practice. Society of Chemical Industry, London, pp 215-221

2. Voronina AV, Semenishchev VS, Nogovitsyna EV, Betenekov ND (2012) A study of ferrocyanide sorbents on hydrated titanium dioxide support using physicochemical methods. Radiochemistry. 54(1):69-74

3. Voronina AV, Semenistchev VS, Betenekov ND, Berezin MA, Yakhina ES (2009) The sorbent for combined extraction of caesium and strontium from high-salted liquid radioactive wastes/ VIII Finnish-Russian symposium on radiochemistry 4-5 September 2009. University of Turcu and Abo Academi University, Finland, Turku, pp 41-42

4. Betenekov ND, Semenistchev VS, Voronina AV (2008) The study of the chemical stability of matrixes for caesium immobilization based on thin-layer inorganic sorbents/SCI conference: IEX 2008 recent advances in ion exchange theory and practice. Society of Chemical Industry, London, pp 211-214

5. Lur'e YY (1979) Handbook on analytical chemistry. Khimiya, Moscow, p 346 